\title{
Nutrition during Pregnancy May Be Associated with Allergic Diseases in Infants
}

\author{
Yuh Ushiyama $^{1, *}$, Kenji Matsumoto ${ }^{2}$, Miwa Shinohara ${ }^{3}$, Hiroshi WaKiguchi ${ }^{4}$, Kentaro SAKar $^{1}$, \\ Tatsushi Komatsu ${ }^{5}$ and Shigeru YамамоTO ${ }^{1}$ \\ ${ }^{1}$ Department of Nutrition, School of Medicine, The University of Tokushima, Tokushima 770-8503, Japan \\ ${ }^{2}$ Department of Allergy, National Children's Hospital, Tokyo 154-8567, Japan \\ ${ }^{3}$ Department of Pediatrics, National Kochi Hospital, Kochi 780-8065, Japan \\ ${ }^{4}$ Department of Pediatrics, Kochi Medical School, Kochi 783-8505, Japan \\ ${ }^{5}$ Department of Nutrition and Food Science, Faculty of Human Life \\ and Environmental Science, Ochanomizu University, Tokyo 112-8610, Japan
}

(Received July 25, 2001)

\begin{abstract}
Summary The prevalence of allergic diseases is high in Japan, even in infants. Their risk for developing allergies is influenced by the antigens in the mother's diet during pregnancy. We hypothesized that, apart from the antigens, hypersensitivity induced through high energy and nutrient intake by mothers during pregnancy may be a factor for allergic diseases in their babies. In this study, we tried to confirm our hypothesis. Allergy histories of parents and their infants, body characteristics and food and nutrient intake were measured by a questionnaire and a food frequency questionnaire, respectively. A total of 2,642 responses were obtained (return rate, 94.7\%). The major allergic diseases in the infants were atopic dermatitis $(6.0 \%)$, food allergy $(3.7 \%)$ and bronchial asthma or asthmatic bronchitis (3.2\%). About $60 \%$ of the infants with allergies had a family history of allergies. Family history of allergy, age of infant, order of birth, head and chest circumferences of infants, BMI of mothers before pregnancy and delivery and intake of lipids (fat and vegetable oil) and vegetables by mothers related positively, and the intake of protein, carbohydrates and milk and its products correlated negatively with allergic diseases in the infants $(p<0.05)$. The results, together with previous reports, suggest that a high intake of energy and lipids (fat and vegetable oil) during pregnancy may accelerate allergic diseases in infants.
\end{abstract}

Key Words nutrition, allergy, mother, infant

The prevalence of asthma (AS) and the other allergic diseases has been rapidly increasing and constitutes a serious social problem in industrialized countries (1). For example, in Japan, a survey conducted by the Ministry of Health and Welfare in 1997 found that $8.6 \%$ of 3 -yr-old children and $9.3 \%$ of adults had food allergies (FA) (2). Infants are not an exception. Regular infant health examinations held by the Ministry throughout the country in 1992 revealed that $6.6 \%$ of the infants were suffering from atopic dermatitis (AD) (3). Many infants have allergy problems even before they beginning weaning from milk-feeding. Allergic diseases of very young infants are thought to be mainly due to antigens transferred from mothers. A major antigen is ovalbumin from hen's egg, and these eggs are responsible for more than $50 \%$ of the food allergies in Japan (4). However, efforts to reduce egg consumption during pregnancy are not necessarily effective for preventing the development of allergies babies $(5,6)$.

These facts led us to consider other factors in the development of allergic diseases in infants. We thought hypersensitivity of the host (infants), induced by certain nutritional conditions of mothers during pregnancy, might be important factors based on the following information. Hypersensitivity and atopic dermatitis (AD) have increased together as diets have become more Westernized (high intake of protein and lipids) in Japan (7-9). The prevalence of allergic diseases in developed countries, where abundant foods are available, is much higher than in developing countries, where the supply of foods is often limited (10). The increased intake of protein- and fat-rich animal foods is associated with a higher prevalence of asthma in Taiwanese teenagers (11). Furthermore, weight reduction by energy restriction improved the conditions of atopic dermatitis (AD) (12).

In this study, we tried to confirm our hypothesis that certain nutritional conditions of mothers during pregnancy induce hypersensitivity and subsequent allergic diseases in their babies.

\section{SUBJECTS AND METHODS}

The survey was done using mothers who participated in a regular infant health examination held by the Pediatric Association of Kochi Prefecture on April 23, 2000 and April 11, 2001. The questionnaire used for this study covered demographic data, allergic history of infants and parents, age of introduction of weaning to food and maternal diet during late pregnancy. Demographic data were obtained from the records of 
regular infant health examinations. The information collected was about mothers (weight gain during pregnancy, body weight, height and age) and infants (birth year, month and day, birth weight, birth height, head circumference and chest circumference).

Diet was assessed using a modified food frequency questionnaire (FFQ) originally prepared by the Japanese Ministry of Health and Welfare. Mothers were questioned about any allergic diseases they and/or their babies have. The FFQ included the main foods frequently consumed in Japan such as rice, bread, noodles, potatoes, fish, meat, eggs, tofu, natto, milk, yogurt, cheese, green vegetables, other vegetables and fruits. Snacks, soft drinks, sugar and lipids were also included in the questionnaire. We used the portion sizes reported by the Japanese Ministry of Health and Welfare (13). The portion sizes were shown as multiples of $80 \mathrm{kcal}$. One multiple was called 1 point. Sizes assigned to 1 point were: rice, half a bowl; bread, half a slice; noodles, a quarter of a noodle; potatoes, two potatoes of hen's egg size; fish, about $70 \mathrm{~g}$; meat, about $50 \mathrm{~g}$; eggs, one egg; tofu, half size of regular package; natto, 1 pack; and milk or yogurt, about $130 \mathrm{~mL}$. Food frequency was classified into 3 or 4 categories and food intake was estimated by the portion size and frequency, and then the intake of foods, energy, protein, lipids and carbohydrates were calculated. This questionnaire was simple enough for mothers to complete by themselves. According to the validity study of this questionnaire by Morimoto et al. (13), estimates of energy, protein and carbohydrates are reliable, however, lipid intake, especially that of the meals with a high lipid energy ratio, is underestimated.

The statistical calculations were made by Chi-square test and logistic regression analysis using Stat View 5.0 (SAS Institute Inc.). A categorical logistic regression model was used to assess the effects of food, energy and nutrient intake (of the mothers) on the allergic diseases (of the infants) after possible confounders such as a family history, sex and feeding method (breast, bottle or mixed) were simultaneously controlled.

\section{RESULTS}

The number of responses was $2,070(94.7 \%)$. Table 1 shows the characteristics of the subjects. The infants were younger than 12-mo-old, the average age being $7.6 \mathrm{mo}$. Average birth weight and height were $3,106 \mathrm{~g}$ and $48.8 \mathrm{~cm}$, respectively. This data approximately matches the Japanese average (14). The mean age of mothers was $29 \mathrm{yr}$, mean BMI (weight $(\mathrm{kg}) /$ height $(\mathrm{m})^{2}$ ) before pregnancy was 20.8 and mean weight gain during pregnancy was $9.5 \mathrm{~kg}$.

Table 2 shows the allergic history in infants and parents. Past allergies were noted in $11.9 \%$ of the infants, $28.6 \%$ of the mothers and $23.6 \%$ of the fathers. According to physicians' diagnoses, $6.0 \%$ of infants have $\mathrm{AD}, 3.7 \%$ have bronchial asthma or asthmatic bronchitis (AS) and 3.2\% have FA. In the mothers 7.1\% have $\mathrm{AD}, 4.3 \%$ have $\mathrm{AS}, 2.7 \%$ have urticaria, $19.0 \%$ have allergic rhinitis and 3.0\% have allergic conjunctivitis. In the fathers $4.0 \%$ have $\mathrm{AD}, 4.3 \%$ have $\mathrm{AS}$, $1.6 \%$ have urticaria, $16.3 \%$ have allergic rhinitis and $1.2 \%$ have allergic conjunctivitis.

The effects of family history on allergic diseases are shown in Table 3. Family history was an important factor for developing allergies. Infants with a family history of allergies showed a suffering ratio nearly a 2 -fold for $\mathrm{AD}, \mathrm{AS}$ and $\mathrm{FA}$ as compared to those without a past history $(p<0.0001)$ (Chi-square test).

Figure 1 shows the ages when the infants first had allergic diseases in 2001 . About $25 \%$ of them had allergic diseases before $3 \mathrm{mo}$ of age and about $75 \%$ before $6 \mathrm{mo}$. Table $4 a-c$ shows the characteristics of infants and mothers. The effects of diets of mothers on the occurrence of allergic diseases in infants were analyzed by logistic regression analysis after including family history, sex, age and order of birth as confounding factors. The family history was related to the incidence of allergies in general $(p<0.01)$. The age of infants was related to the incidence of food allergies $(p<0.01)$. The order of birth was related to the incidence of asthma $(p<0.05)$.

Table 1. Characteristics of infants and mothers $(n=2,070)$.

\begin{tabular}{llc}
\hline & & Mean \pm SD \\
\hline \multirow{2}{*}{ Infants } & Age (mo) & $7.6 \pm 2.8$ \\
& Duration of pregnancy (wk) & $39.0 \pm 1.8$ \\
& Weight at birth (g) & $3,106 \pm 421$ \\
& Height at birth (g) & $48.8 \pm 2.2$ \\
Mothers & Age (y) & $29.2 \pm 4.3$ \\
& BMI (before pregnancy) & $20.8 \pm 2.8$ \\
& Increase in weight during & $9.5 \pm 4.3$ \\
& $\quad$ pregnancy $(\mathrm{kg})$ & \\
\hline
\end{tabular}

Table 2. Number and prevalence of allergic diseases in infants and parents.

\begin{tabular}{|c|c|c|c|}
\hline & $\begin{array}{c}\text { Infant } \\
n=2,070\end{array}$ & $\begin{array}{c}\text { Mother } \\
n=2,070\end{array}$ & $\begin{array}{c}\text { Father } \\
n=2,070\end{array}$ \\
\hline Allergic disease & $247(11.9 \%)$ & $593(28.6 \%)$ & $488 \quad(23.6 \%)$ \\
\hline Atopic dermatitis & $124 \quad(6.0 \%)$ & $146 \quad(7.1 \%)$ & $82 \quad(4.0 \%)$ \\
\hline Asthma & $77 \quad(3.7 \%)$ & $88 \quad(4.3 \%)$ & $89 \quad(4.3 \%)$ \\
\hline Food allergies & $66 \quad(3.2 \%)$ & $-\quad-$ & - \\
\hline Urticaria & $-\quad-$ & $56 \quad(2.7 \%)$ & $33(1.6 \%)$ \\
\hline Allergic rhinitis & - & $393(19.0 \%)$ & $337(16.3 \%)$ \\
\hline Allergic conjunctivitis & - & $63 \quad(3.0 \%)$ & $25 \quad(1.2 \%)$ \\
\hline
\end{tabular}


Table 3. Prevalence of allergic diseases in infants with or without family history of allergies. Infants with a family history of allergic diseases were more susceptible for all three allergic diseases, atopic dermatitis, food allergies and bronchial asthma, when compared to those without a family history of allergies $(p<0.0001)$.

\begin{tabular}{|c|c|c|c|c|c|}
\hline & \multicolumn{2}{|c|}{ Family history } & \multirow{2}{*}{ Odds ratio } & \multirow{2}{*}{$\chi^{2}$} & \multirow{2}{*}{$p$ value } \\
\hline & Yes $(\%)$ & No (\%) & & & \\
\hline \multicolumn{6}{|c|}{ Atopic dermatitis } \\
\hline Yes & $109(10.6)$ & $69 \quad(4.6)$ & 2.45 & 32.67 & $<0.000001$ \\
\hline No & 919 (89.4) & $1,431 \quad(95.4)$ & & & \\
\hline \multicolumn{6}{|c|}{ Food allergies } \\
\hline Yes & $67 \quad(6.8)$ & $42 \quad(2.8)$ & 2.53 & 21.76 & $<0.000001$ \\
\hline No & $918 \quad(93.2)$ & $1,458 \quad(97.2)$ & & & \\
\hline \multicolumn{6}{|c|}{ Bronchial asthma } \\
\hline Yes & $70 \quad(7.1)$ & $69 \quad(3.4)$ & 2.17 & 16.79 & $<0.00001$ \\
\hline No & 916 (92.9) & $1,449 \quad(96.6)$ & & & \\
\hline
\end{tabular}

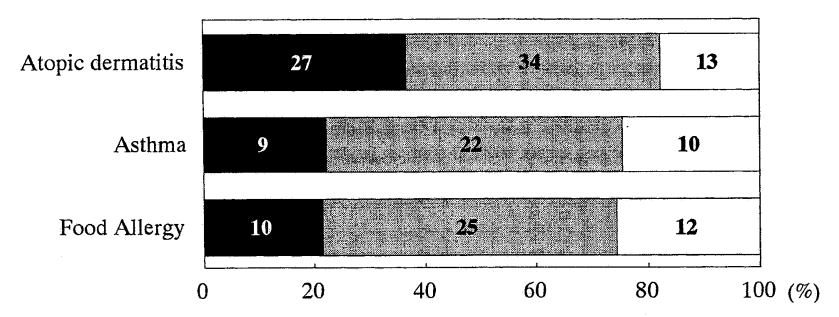

Fig. 1. Age of onset of each allergic disease in infants during the first year of life. Actual number of infants who developed each allergic disease is shown in the

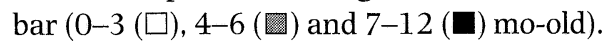

Head and chest circumferences at birth were positively related to food allergies $(p<0.05)$. The BMI of mothers before pregnancy and delivery associated positively with food allergies in infants $(p<0.05)$.

The intake of lipids (mainly fat and vegetable oil) and vegetables by mothers related positively (Table $5 \mathrm{c}$ ), and the intake of protein, carbohydrates and milk and its products negatively (Table $5 \mathrm{a}, \mathrm{c}$ ) to allergic diseases in infants $(p<0.05)$.

\section{DISCUSSION}

Usually antigens are the major factors of allergic diseases. However, we thought that hypersensitivity of the host is also an important factor. In this study, we tried to confirm our hypothesis that the intake of certain nutrients as well as the nutritional status of mothers during pregnancy induces hypersensitivity and subsequent allergic diseases in their babies. Our subjects were 2,070 mothers and their babies who participated in 20002001 infant health check-ups in Kochi Prefecture, Japan. About $13.1 \%$ of the children were suffering from allergies. Among them, atopic dermatitis $(\mathrm{AD})$ was found in $6.0 \%$, asthma in (AS) $3.7 \%$ and food allergies (FA) in $3.2 \%$ of the infants (Table 2). For observing the effects of mother's diets on the allergic diseases in their infants, data before the increased effects of weaning to food is desirable; therefore, we used the data of infants younger than $12 \mathrm{mo}$. However, when we compared the results between the infants before and after 6 mo-old, there was not a significant difference in the prevalence of allergic diseases $(p>0.05)$ because most of the infants (about 80\%) had developed allergic disease(s) before 6 mo of age (Fig. 1). For this reason, and the reason that we did not want to lose the data obtained for infants older than $6 \mathrm{mo}$, all the data for infants younger than 12 mo was used for this study. Although, in this health examination, children younger than 24 mo were included, all were younger than 18 mo.

Mothers with allergic infants had a higher intake of lipids (mainly fat and vegetable oil) than those with non-allergic infants. We concluded that the intake of fish, and therefore, fish oil was not different between the two groups because there were no differences in the quantities and types of fish.

The high intake of lipids as a factor in the development of allergies is supported by the annual national nutrition survey (7) and the allergy survey (9) in Japan. Mean lipid intake was $18.0 \mathrm{~g}$ (15\% of energy) in 1950 , $55.2 \mathrm{~g} \mathrm{(23 \%}$ of energy) in 1975 and $57.9 \mathrm{~g}$ ( $26 \%$ of energy) in 1998 (7). The change in lipid intake was mainly due to the increased intake of fat and vegetable oil. Prevalence of asthma also increased parallel to increased lipid intake. The prevalence was $1.71 \%$ in $1971,3.62 \%$ in 1981 and $5.37 \%$ in 1991 (9). The relationship between lipid intake and development of allergies is also supported by other studies. The $n-6$ and $n-$ 3 unsaturated fatty acids have opposite effects on allergies. Excessive intake of $n-6$ unsaturated fatty acids induces allergies by increasing arachidonic acid concentration. Arachidonic acid increases inflammatory diseases by the production of lipid mediators (e.g., prostaglandin, thromboxane, leukotrienes, platelet-aggregating factor), which contracts smooth muscle, accelerates permeability of blood vessels and causes Type1 allergies. Huang et al. observed that fat-rich foods are related to asthma in Taiwanese adolescents (11). On the other hand, there are many reports that $n-3$ unsaturated fatty acids reduce the prevalence of asthma by decreasing the production of arachidonic acid from linoleic acid (15-17). Satomi et al. (15) observed a negative relationship between $n-3$ fatty acids and asthma. 
Table 4a. Crude and adjusted odds ratio, and 95\% confidence intervals of atopic dermatitis by characteristics of infants and mothers.

\begin{tabular}{llllll}
\hline & $\begin{array}{l}\text { Atopic dermatitis } n=84 \\
\text { No allergy } n=1,824\end{array}$ & Crude OR & adj OR ${ }^{1}$ & $(95 \%$ CI $)$ & $p$ value $^{2}$ \\
\hline \multirow{2}{*}{ Infants } & Family history & 2.02 & 1.94 & $(1.21-3.11)$ & $0.006^{* *}$ \\
& Sex & 0.67 & 0.66 & $(0.41-1.06)$ & 0.09 \\
& Age & 0.96 & 0.94 & $(0.86-1.02)$ & 0.11 \\
& Feeding & 1.04 & 1.19 & $(0.64-2.24)$ & 0.58 \\
& Order of birth & 1.13 & 1.17 & $(0.86-1.59)$ & 0.33 \\
& Duration of pregnancy & 1.12 & 1.13 & $(0.96-1.34)$ & 0.15 \\
& Weight at birth & 1.00 & 1.00 & $(1.00-1.00)$ & 0.37 \\
& Height at birth & 1.11 & 1.09 & $(0.97-1.21)$ & 0.14 \\
& Head circumference at birth & 1.05 & 1.06 & $(0.89-1.14)$ & 0.46 \\
Mothers & 1.00 & 1.01 & $(0.95-1.07)$ & 0.93 \\
& Agest circumference at birth & 1.01 & 1.00 & $(0.98-1.14)$ & 0.90 \\
& BMI (before pregnant) & 1.07 & 1.06 & $(0.96-1.12)$ & 0.33 \\
\hline
\end{tabular}

BMI, body mass index.

${ }^{1}$ Adjusted for family history, sex, order of birth and age of infants.

${ }^{2} p$ value of logistic regression. ${ }^{* *} p<0.01$.

Table $4 \mathrm{~b}$. Crude and adjusted odds ratio, and 95\% confidence intervals of food allergies by characteristics of infants and mothers.

\begin{tabular}{llcccc}
\hline & Food allergy $n=32$ & & & \\
& No allergy $n=1,824$ & Crude OR & adj OR ${ }^{1}$ & $(95 \%$ CI $)$ & $p$ value \\
\hline \multirow{2}{*}{ Infants } & Family history & 2.83 & 2.86 & $(1.36-6.03)$ & $0.006^{* *}$ \\
& Sex & 0.70 & 0.67 & $(0.32-1.40)$ & 0.29 \\
& Age & 1.23 & 1.23 & $(1.07-1.41)$ & $0.005^{* *}$ \\
& Feeding & 1.03 & 0.94 & $(0.41-2.16)$ & 0.89 \\
& Order of birth & 0.68 & 0.70 & $(0.39-1.24)$ & 0.22 \\
& Duration of pregnancy & 0.95 & 0.96 & $(0.83-1.11)$ & 0.58 \\
& Weight at birth & 1.00 & 1.00 & $(1.00-1.00)$ & 0.32 \\
& Height at birth & 1.10 & 1.10 & $(0.93-1.30)$ & 0.28 \\
& Head circumference at birth & 1.27 & 1.24 & $(1.05-1.46)$ & $0.01^{*}$ \\
& Chest circumference at birth & 1.16 & 1.16 & $(0.94-1.13)$ & $0.03^{*}$ \\
Age & 1.00 & 1.03 & $(1.02-1.23)$ & 0.50 \\
& BMI (before pregnant) & 1.11 & 1.12 & $(1.00-1.23)$ & $0.02^{*}$ \\
& BMI (before delivery) & 1.10 & 1.11 & & $0.049^{*}$ \\
\hline
\end{tabular}

\footnotetext{
${ }^{1}$ Adjusted for family history, sex, order of birth and age.

${ }^{2} p$ value of logistic regression. ${ }^{* *} p<0.01,{ }^{*} p<0.05$.
}

Lee et al. (16) administered fish oil rich in eicosapentaenoic acid and docosahexaenoic acid, and observed a decrease in leukotrienes B4 and other metabolites of the 5-lipoxygenase pathway and an increase in leukotrienes B5 from neutrophils and monocytes, which release inflammatory substances and induce atricture of the respiratory tract and dermatitis. There are also many reports that eicosapentaenoic acid prevents chemical mediators of inflammation. Nagakura et al. (17) studied the effects of fish oil and olive oil on hospitalized patients and found that fish oil was effective against asthma. However, there are many clinical studies that have been unable to demonstrate any positive effects of supplementing $n-3$ fatty acids for reducing asthma. In our study, the consumption of fish, which was the main source of $n-3$ unsaturated fatty acids, was not different between the mothers of infants with or without allergic diseases. This suggests that the excessive intake of fat and vegetable oil (rich in $n-6$ unsaturated fatty acids) during pregnancy may be one of the main predictors of asthma and food allergies in infants. By the validity study of Morimoto et al. (13), this survey underestimates the lipid intake. If we take this nature of the survey into consideration, the conclusion must be further emphasized.

Mothers of infants with food allergies had a higher BMI than those of non-allergic infants (Table 4b). This indicates that a high energy intake by mothers might cause an increased risk of allergic problems in their children. A higher BMI in adult life is associated with a 
Table 4c. Crude and adjusted odds ratio, and 95\% confidence intervals of asthma by characteristics of infants and mothers.

\begin{tabular}{llcccc}
\hline & Asthma $n=63$ & Crude OR & adj OR & & \\
& No allergy $n=1,824$ & & $(95 \%$ CI $)$ & $p$ value \\
\hline \multirow{2}{*}{ Infants } & Family history & 2.11 & 2.23 & $(1.31-3.79)$ & $0.003^{* *}$ \\
& Sex & 0.67 & 0.67 & $(0.39-1.14)$ & 0.14 \\
& Age & 1.07 & 1.07 & $(0.97-1.18)$ & 0.15 \\
& Feeding & 1.19 & 1.29 & $(0.67-2.47)$ & 0.44 \\
& Order of birth & 1.81 & 1.83 & $(1.35-2.47)$ & $<0.0001^{* *}$ \\
& Duration of pregnancy & 0.95 & 0.97 & $(0.86-1.09)$ & 0.60 \\
& Weight at birth & 1.00 & 1.00 & $(1.00-1.00)$ & 0.75 \\
& Height at birth & 0.97 & 0.94 & $(0.87-1.05)$ & 0.29 \\
& Head circumference at birth & 1.13 & 1.04 & $(0.81-1.07)$ & 0.65 \\
& Chest circumference at birth & 0.97 & 0.93 & $(0.94-1.07)$ & 0.33 \\
& Age & 1.05 & 1.00 & $(0.95-1.13)$ & 0.43 \\
& BMI (before pregnant) & 1.05 & 1.04 & $(0.96-1.14)$ & 0.32 \\
\hline
\end{tabular}

\footnotetext{
. 1 Adjusted for family history, sex, order of birth and age.
}

${ }^{2} p$ value of logistic regression. ${ }^{* *} p<0.01$.

Table 5a. Crude and adjusted odds ratio, and 95\% confidence intervals of atopic dermatitis by intake of food (points ${ }^{1}$ ), energy and nutrients.

\begin{tabular}{|c|c|c|c|c|}
\hline $\begin{array}{l}\text { Atopic dermatitis } n=84 \\
\text { No allergy } n=1,824\end{array}$ & Crude OR & adj $\mathrm{OR}^{2}$ & $(95 \% \mathrm{CI})$ & $p$ value $^{3}$ \\
\hline Staple diet & 1.04 & 1.03 & $(0.95-1.11)$ & 0.47 \\
\hline Potatoes & 1.21 & 1.06 & $(0.37-2.99)$ & 0.92 \\
\hline Fish & 0.53 & 0.51 & $(0.24-1.07)$ & 0.08 \\
\hline Meat & 1.00 & 0.92 & $(0.59-1.44)$ & 0.72 \\
\hline Egg & 0.98 & 0.88 & $(0.43-1.80)$ & 0.72 \\
\hline Tofu/natto & 0.70 & 0.65 & $(0.42-1.01)$ & 0.05 \\
\hline Milk/milk products & 0.75 & 0.79 & $(0.66-0.96)$ & $0.02^{*}$ \\
\hline Vegetable & 0.78 & 0.63 & $(0.37-1.08)$ & 0.09 \\
\hline Fruit & 1.00 & 1.00 & $(0.76-1.32)$ & 0.99 \\
\hline Snack & 0.75 & 0.85 & $(0.54-1.35)$ & 0.50 \\
\hline Sugar & 1.25 & 1.18 & $(0.82-1.70)$ & 0.39 \\
\hline Fatty foods (include butter, fly food and fatty meat) & 0.95 & 0.90 & $(0.71-1.14)$ & 0.38 \\
\hline Energy & 1.00 & 1.00 & $(1.00-1.00)$ & 0.11 \\
\hline Protein/energy & 0.87 & 0.88 & $(0.79-0.98)$ & $0.02^{*}$ \\
\hline Lipids/energy & 0.97 & 0.98 & $(0.94-1.02)$ & 0.26 \\
\hline Carbohydrates/energy & 1.03 & 1.03 & $(0.99-1.06)$ & 0.10 \\
\hline
\end{tabular}

\footnotetext{
${ }^{1}$ Values are expressed as points. One point is $80 \mathrm{kcal}$.

${ }^{2}$ Adjusted for family history, sex, order of birth and age.

${ }^{3} p$ value of logistic regression. ${ }^{*} p<0.05$.
}

higher prevalence of asthma and wheezing among individuals (18). In Britain, the rise in asthma among children and in adults has been accompanied by an increase in the prevalence of overweight and obesity (19). A positive association between body mass index, asthma and persistent wheezing has been reported in children (19), and there is clear evidence that excessive weight is associated with asthma in children (19). BMI was a significant predictor of atopy, allergic symptoms and bronchial hyper-responsiveness in teenage girls (20). Parallel increases in obesity and allergies in Japan also support our present findings. Average BMI in
Japanese more than $20 \mathrm{yr}$ of age was 21.6 in 1950 , 21.7 in 1970 and 22.8 in 1998 (21). The increase in allergies is as discussed above.

In this study, the relationship of protein intake and allergies was contradictory from our hypothesis (Table 5). We thought that a high intake of high-quality protein increases allergic diseases, because the increase in diseases has happened in parallel with the increase of high-quality protein intake in Japan (7). However, the increase of high-quality protein usually comes together an increase in fatty animal foods. Therefore, it is easy to misunderstand that high protein intake increases aller- 
Table 5b. Crude and adjusted odds ratio, and $95 \%$ confidence intervals of food allergies by intake of food (points ${ }^{1}$ ), energy and nutrients.

\begin{tabular}{|c|c|c|c|c|}
\hline $\begin{array}{l}\text { Food allergies } n=32 \\
\text { No allergy } n=1,824\end{array}$ & Crude OR & $\operatorname{adj} \mathrm{OR}^{2}$ & $(95 \% \mathrm{CI})$ & $p$ value $^{3}$ \\
\hline Staple diet & 1.02 & 1.02 & $(0.90-1.16)$ & 0.72 \\
\hline Potatoes & 1.83 & 1.90 & $(0.42-8.69)$ & 0.41 \\
\hline Fish & 0.82 & 0.81 & $(0.30-2.20)$ & 0.68 \\
\hline Meat & 1.52 & 1.60 & $(0.87-2.96)$ & 0.13 \\
\hline Egg & 0.58 & 0.62 & $(0.20-1.88)$ & 0.40 \\
\hline Tofu/natto & 1.14 & 1.05 & $(0.61-1.83)$ & 0.85 \\
\hline Milk/milk products & 1.13 & 1.16 & $(0.91-1.49)$ & 0.23 \\
\hline Vegetable & 1.32 & 1.46 & $(0.69-3.09)$ & 0.32 \\
\hline Fruit & 0.98 & 1.01 & $(0.66-1.54)$ & 0.98 \\
\hline Snack & 1.29 & 1.31 & $(0.64-2.66)$ & 0.46 \\
\hline Sugar & 0.53 & 0.57 & $(0.31-1.06)$ & 0.08 \\
\hline Fatty foods (include butter, fly food and fatty meat) & 1.15 & 1.18 & $(0.83-1.67)$ & 0.36 \\
\hline Energy & 1.00 & 1.00 & $(1.00-1.00)$ & 0.50 \\
\hline Protein/energy & 1.05 & 1.03 & $(0.87-1.21)$ & 0.75 \\
\hline Lipids/energy & 1.03 & 1.03 & $(0.98-1.09)$ & 0.26 \\
\hline Carbohydrates/energy & 0.97 & 0.97 & $(0.93-1.02)$ & 0.29 \\
\hline
\end{tabular}

\footnotetext{
${ }^{1}$ Values are expressed as points. One point is $80 \mathrm{kcal}$.

${ }^{2}$ Adjusted for family history, sex, order of birth and age.

${ }^{3} p$ value of logistic regression.
}

Table 5c. Crude and adjusted odds ratio, and 95\% confidence intervals of asthma by intake of food (points ${ }^{1}$ ), energy and nutrients.

\begin{tabular}{lcccc}
\hline Asthma $n=63$ & Crude OR & adj OR & $(95 \%$ CI $)$ & $p$ value \\
No allergy $n=1,824$ & & & $(0.90-1.08)$ & 0.82 \\
Staple diet & 1.00 & 0.99 & $(0.72-6.86)$ & 0.17 \\
Potatoes & 2.22 & 2.22 & $(0.42-1.73)$ & 0.66 \\
Fish & 0.90 & 0.86 & $0.55-1.56)$ & 0.78 \\
Meat & 0.77 & 0.93 & $(0.70-3.22)$ & 0.29 \\
Egg & 1.35 & 1.51 & $(0.97-2.00)$ & 0.08 \\
Tofu/natto & 1.45 & 1.39 & $(0.81-1.21)$ & 0.93 \\
Milk/milk products & 0.99 & 0.99 & $(1.06-3.18)$ & $0.03^{*}$ \\
Vegetable & 1.71 & 1.84 & $(0.74-1.38)$ & 0.96 \\
Fruit & 1.00 & 1.01 & $(0.66-1.90)$ & 0.68 \\
Snack & 1.07 & 1.12 & $(0.78-1.78)$ & 0.45 \\
Sugar & 1.35 & 1.17 & $(1.02-1.71)$ & $0.04^{*}$ \\
Fatty foods (include butter, fly food and fatty meat) & 1.35 & 1.32 & $(1.00-1.00)$ & 0.46 \\
Energy & 1.00 & 1.00 & $(0.92-1.17)$ & 0.58 \\
Protein/energy & 1.01 & 1.04 & $(1.00-1.08)$ & $0.03^{*}$ \\
Lipids/energy & 1.04 & 1.04 & $(0.93-1.00)$ & $0.04^{*}$ \\
Carbohydrates/energy & 0.97 & 0.97 & & \\
\hline
\end{tabular}

\footnotetext{
${ }^{1}$ Values are expressed as points. One point is $80 \mathrm{kcal}$.

${ }^{2}$ Adjusted for family history, sex, order of birth and age.

${ }^{3} p$ value of logistic regression. ${ }^{*} p<0.05$.
}

gic diseases, even though high fat intake is the real factor. Further studies are required concerning the effect of protein on allergies.

The relationship of vegetable intake and allergies was also contradictory from our assumption (Table 5). There has been no report that shows vegetable intake increases allergies. Some studies have shown that antioxidants such as vitamin $\mathrm{C}$ in vegetables and fruits prevent asthma $(22,23)$. We again think that this con- tradictory result was derived from the high lipid intake paralleled by high vegetable intake. The lipid intake and vegetable intake by mothers in this study were positively related ( $r=0.36, p<0.0001$, data is not shown). From such background information, we cannot conclude that high vegetable intake is a factor that contributes to allergies. Further studies are required.

The present results, together with previous reports from other researchers, suggest that the high intake of 
energy and lipids (mainly fat and vegetable oil) during pregnancy may accelerate allergic diseases in infants.

\section{REFERENCES}

1) Burr ML. 1989. Changes in asthma prevalence: two surveys 15 years apart. Arch Dis Child 64: 1452-1456.

2) Iikura Y. 1998. Shokumotsu arerugi taisaku kentou iinkai heisei 9 nendo houkokusho, p 6-11 (in Japanese).

3) Kouseishou Jidoukateikyoku Boshieiseika. 1994. Heisei 4 nendo atopisei shikkan jittai tyousa houkokusho, $p$ 50 (in Japanese).

4) Iikura Y. 1997. Shokumotsu arerugi taisaku kentou iinkai heisei 8 nendo houkokusho, p 4-8 (in Japanese).

5) Falth-Magnusson K, Kjellman N-IM. 1987. Development of atopic disease in babies whose mothers were receiving exclusion diet during pregnancy-A randomized study. J Allergy Clin Immunol 80: 869-875.

6) Falth-Magnusson K, Kjellman N-IM. 1992. Allergy prevention by maternal elimination diet during late pregnancy-A 5-year follow-up of a randomized study. $J$ Allergy Clin Immunol 89: 709-713.

7) Nutrition Division, Public Health Bureau, Ministry of Health and Welfare. 2000. Kokumin eiyo no genjo (The National Nutrition Survey, 1998), p 145-151. Tokyo Daiichi Shuppan, Tokyo (in Japanese).

8) Mikawa H. 1998. Epidemiology of allergic disease. $J$ Pediatr Pract 61: 471-474 (in Japanese).

9) Ueda H. 2000. Atopy sei hifuen no ekigaku. Jpn J Pediatr Med 32: 986-992 (in Japanese).

10) The International Study of Asthma and Allergies in Childhood (ISAAC) Steering Committee. 1998. Worldwide variation in prevalence of symptoms of asthma, allergic rhinoconjunctivitis, and atopic eczema: ISAAC. Lancet 351: 1225-1232.

11) Huang S-L, Lin K-C, Pan W-H. 2001. Pan dietary factors associated with physician-diagnosed asthma and allergic rhinitis in teenagers: analyses of the first nutrition and health survey in Taiwan. Clin Exp Allergy 31: 259-264.

12) Kouda K, Tanaka T, Takeuchi H, Takeuchi A,
Nakamura H, Takigawa M. 2000. Low-energy diet in atopic dermatitis patients: clinical findings and DNA damage. J Physiol Anthropol Appl Human Sci 19: 225228.

13) Morimoto A, Takase S, Hada K, Hosoya N. 1977. Evaluation of a "convenient method" for the estimation of dietary food consumption. Jpn J Nutr 35: 235-245.

14) Health and Welfare Statistics Association. 2000. Journal of Health and Welfare Statistics (special ed) Kokumin eisei no doukou: 43-47 (in Japanese).

15) Satomi H, Minowa M, Hatano S, Nagakura T, Iikura Y, 1994. An epidemiological study of the preventive effect of dietary fish on bronchial asthma. Bull Inst Public Health 43: 305-314.

16) Lee TH, Hoover RL, Williams JD, Sperling RI, Ravalese J III, Spur BW, Robinson DR, Corey EJ, Lewis RA, Austen KF. 1985. Effect of dietary enrichment with eicosapentaenoic and docosahexaenoic acids on in vitro neutrophil and monocyte leukotriene generation and neutrophil function. N Eng J Med 312: 1217-1224.

17) Nagakura T, Sugimoto H. 1997. Polyunsaturated acids and asthma. Asthma 10: 31-37 (in Japanese).

18) Shaheen SO, Sterne JA, Montgomery SM, Azima H. 1999. Birth weight, body mass index and asthma in young adults. Thorax 54: 396-400.

19) Figueroa Munoz JI, Chinn S, Rona RJ. 2001. Association between obesity and asthma in 4-11 years old children in the UK. Thorax 56: 133-137.

20) Huang SL, Shiao GM, Chou P. 1999. Association between body mass index and allergy in teenage girls in Taiwan. Clin Exp Allergy 29: 323-329.

21) Kenko Eiyou Jouhou Kenkyukai Eiyou Tyousa Kenkyu Han. 1998. Sengo showa no eiyou doukou: Kokumin eiyou tyousa 40 nen wo furikaeru, p 118-125. Tokyo Daiichi Shuppan, Tokyo (in Japanese).

22) Weiss ST. 1997. Diet as a risk factor for asthma. Ciba Found Symp 206: 244-257.

23) Forastiere F, Pistelli R, Sestini P, Fortes C, Renzoni E, Rusconi F, Dell'Orco V, Ciccone G, Bisanti L. 2000. Consumption of fresh fruit rich in vitamin $\mathrm{C}$ and wheezing symptoms in children. Thorax 55: 283-288. 